\title{
Neuroblastoma-A Neural Crest Derived Embryonal Malignancy
}

\author{
John Inge Johnsen*, Cecilia Dyberg and Malin Wickström \\ Childhood Cancer Research Unit, Department of Women's and Children's Health, Karolinska Institutet (KI), Stockholm, \\ Sweden
}

Neuroblastoma is a neural crest derived malignancy of the peripheral nervous system and is the most common and deadliest tumor of infancy. It is characterized by clinical heterogeneity with a disease spectrum ranging from spontaneous regression without any medical intervention to treatment resistant tumors with metastatic spread and poor patient survival. The events that lead to the development of neuroblastoma from the neural crest have not been fully elucidated. Here we discuss factors and processes within the neural crest that when dysregulated have the potential to be initiators or drivers of neuroblastoma development. A more precise biological understanding of neuroblastoma causes and cell of origin is highly warranted. This will give valuable information for the development of medicines that specifically target molecules within neuroblastoma cells and also give hint about the mechanisms behind treatment resistance that is frequently seen in neuroblastoma.

Keywords: neuroblastoma, neural crest, tumorigenesis, oncogenic drivers, mutation

\section{OPEN ACCESS}

Edited by:

Sabine Wislet,

University of Liège, Belgium

Reviewed by:

Wei-jiang Zhao,

Shantou University Medical College,

China

Aixa Victoria Morales, Cajal Institute (CSIC), Spain

${ }^{*}$ Correspondence: John Inge Johnsen john.inge.johnsen@ki.se

Received: 31 October 2018 Accepted: 11 January 2019 Published: 29 January 2019

Citation: Johnsen Jl, Dyberg C and Wickström M

(2019) Neuroblastoma-A Neural Crest Derived Embryonal Malignancy.

Front. Mol. Neurosci. 12:9. doi: 10.3389/fnmol.2019.00009

\section{INTRODUCTION}

Neuroblastoma is a malignancy of the sympathetic nervous system that almost exclusively occurs in early childhood. Neuroblastoma is a relatively rare disease affecting 1 in 8,000 live births and represents $6 \%-10 \%$ of all childhood tumors. However, neuroblastoma accounts for $12 \%-15 \%$ of all childhood cancer related death and is the most common and deadly extracranial tumor of childhood (Brodeur, 2003; Johnsen et al., 2009; Maris, 2010; Park et al., 2010). The median age at diagnosis for neuroblastoma is $17-18$ months and approximately $40 \%$ of the patients are younger than 1 year at diagnosis whereas less than $5 \%$ of the patients are older than 10 years (London et al., 2005; Maris, 2010; Park et al., 2010).

Histopathologically, neuroblastoma has been defined as a small blue round cell tumor of childhood, a group of diagnoses consisting mostly of undifferentiated pediatric malignancies. The cell of origin for neuroblastoma has yet to be precisely defined but probably derives from sympathoadrenal progenitor cells within the neural crest that differentiate to sympathetic ganglion cells and adrenal catecholamine-secreting chromaffin cells (L'Abbate et al., 2014). Neuroblastoma manifest anywhere along the sympathetic nervous system, the majority are located in the abdomen along the sympathetic chain and in the adrenal gland medullary region. Neuroblastoma is characterized by wide clinical heterogeneity which includes everything between spontaneous regression or differentiation and treatment-refractory progression despite intensive therapy. This heterogeneity is correspondingly reflected in the survival of neuroblastoma patients spanning from 85 to $90 \%$ cure rate in patients with low- and intermediate-risk disease to less than $50 \%$ in patients diagnosed with high-risk neuroblastoma (Pearson et al., 2008; Matthay et al., 2009; Valteau-Couanet et al., 2014; Ladenstein et al., 2017). 
Since the majority of neuroblastoma patients are diagnosed with high-risk disease in which current intensive therapies are not effective, the development of new treatment options for this group of patients as well as for those patients with relapsed or recurrent tumors, where the current overall survival is less than $10 \%$, is urgently needed. To accomplish this there is also a need for a more thorough and precise knowledge of the molecular landscape of neuroblastoma cells and their interactions with the surrounding microenvironment.

\section{MOLECULAR PATHOGENESIS OF NEUROBLASTOMA}

A number of biological and genetic markers of neuroblastoma have been investigated in order to facilitate diagnosis, prognosis and monitoring of treatment effects in patients with neuroblastoma (Riley et al., 2004). However, probably due to the complexity of the disease, no single biological or genetically marker has proven useful for accurate diagnosis. Instead a combination of imaging techniques, measurement of secreted catecholamine metabolites, cell surface markers and chromosomal and genetic analysis of tumor DNA are used for diagnosis and risk classification in patients with neuroblastoma.

\section{Cell Surface Markers in Neuroblastoma}

One surface antigen that is abundantly present in the outer membrane of all neuroblastomas regardless of disease stage is disialoganglioside (GD2). During embryonal development, GD2 is expressed on neural and mesenchymal stem cells, whereas postnatal expression of GD2 is in normal tissues restricted to neural cells located in the peripheral and central nervous system as well as in melanocytes of the skin (Lammie et al., 1993; Yanagisawa et al., 2011). The detailed function of GD2 during normal development is currently not understood. However, gangliosides, including GD2 have been proposed to be important for the formation and maintenance of membrane microdomains in neural tissues (Ohmi et al., 2012). Although immunohistochemical detection of GD2 in tumor tissue samples can be used as an indicator of neuroblastoma, the most valuable consequence of GD2 expression has been the utilization of GD2 as a neoantigen for immunotherapy. Anti-GD2 antibodies have for the last 20 years been successfully applied as a treatment option for high-risk neuroblastoma and recent studies have shown further increased survival of patients with high-risk neuroblastoma treated with a combination of chimeric anti-GD2 antibodies, GM-CSF and IL-2 suggesting more systematic evaluation of this treatment regimen (Yu et al., 2010; Ladenstein et al., 2013; Mody et al., 2017).

The neurotrophin receptors, $\operatorname{Trk} A, \operatorname{TrkB}$ and $\operatorname{Trk} C$ are receptor tyrosine kinases that each is crucial for proper development and maintenance of the peripheral nervous system (Brodeur, 2018). Numerous studies have shown that TrkA and TrkB have important implications for the diverse pathology observed in neuroblastoma patients (Brodeur et al., 1997, 2009; Thiele et al., 2009). High expression of TrkA is a hallmark for low-grade neuroblastomas prone to spontaneous regression or differentiation whereas high expression of TrkB has been linked to high-risk disease and poor patient survival (Kogner et al., 1993; Nakagawara et al., 1993, 1994). In addition, high-risk neuroblastoma also expresses the TrkB ligand brain-derived neurotrophic factor (BNDF) resulting autocrine/paracrine tumor cell survival (Acheson et al., 1995; Matsumoto et al., 1995).

\section{Chromosomal and Genetic Markers in Neuroblastoma}

Pediatric cancers harbor substantial less genomic aberrations and mutations compared to adult tumors (Cheung et al., 2012; Molenaar et al., 2012; Pugh et al., 2013). Low-risk neuroblastoma often present with whole chromosomal gains and the tumor cells are frequently hyperdiploid (near triploid or penta/hexaploid) in their chromosomal make-up (Ambros et al., 2009). On the contrary, high-risk neuroblastoma contains segmental chromosomal aberrations that affect only a part of a given chromosome (Carén et al., 2010; Morgenstern et al., 2014; Irwin and Park, 2015; Matthay et al., 2016). The most frequent chromosomal aberration associated with poor prognosis in neuroblastoma is somatically acquired amplification of the MYCN gene, hemizygous deletions of $1 \mathrm{p}$ and $11 \mathrm{q}$, and segmental gain of $17 q$ (Brodeur, 2003; Maris, 2010). In addition, high-risk neuroblastomas can also display genomic rearrangements at chromosomal region $5 \mathrm{p} 15.33$ which is located proximal of the telomerase reverse transcriptase gene (TERT) resulting in chromosomal changes, DNA methylation and enhanced TERT expression (Peifer et al., 2015; Valentijn et al., 2015).

Genomic surveys using exome- and whole-genome sequencing of neuroblastoma tissue samples showed a low somatic mutation count (12-18, median 15) and that there is no single genetic mutation event that can explain the development of all neuroblastoma cases (Cheung et al., 2012; Molenaar et al., 2012; Pugh et al., 2013). The anaplastic lymphoma kinase $(A L K)$ is the most frequent mutated gene detected in $7 \%-10 \%$ primary neuroblastomas. $A L K$ mutations are also present in almost all cases of familial neuroblastomas which account for $1 \%-2 \%$ of the neuroblastoma cases (Mossé et al., 2008). Germline loss-of-function mutations of the pairedlike homeobox $2 B$ (PHOX2B) gene has also been reported in familial neuroblastoma as well as in approximately $4 \%$ of high-risk spontaneous neuroblastoma cases (Mossé et al., 2008; Cheung et al., 2012; Pugh et al., 2013). In addition, somatic mutations in primary neuroblastomas has been reported for the transcriptional regulator ATRX $(2.5 \%$ inactivating mutations), the tumor suppressor p53 (TP53; 1\%-2\% in primary tumors, $10 \%$ in recurrent and relapsed tumors) gene, ARID1A/1B (2\%-3\% inactivating mutations), PTPN11 $(2.9 \%$ activating mutations), MYCN (1.7\% activating mutations), NRAS (0.83\% activating mutations) and BRCA2 (Cheung et al., 2012; Molenaar et al., 2012; Pugh et al., 2013; Brodeur and Bagatell, 2014). However, the importance and relevance of several of these mutations for neuroblastoma development have yet to be identified. Other less frequently detected 
mutations in primary neuroblastomas are often in genes in which the protein is involved in the regulation of signal transduction pathways as exemplified by detection of genetic lesions in the MAPK signaling cascade in 3\%-5\% of primary neuroblastomas (Pugh et al., 2013) and in 28\% of genes responsible for correct neuritogenesis, many in the Rho family of genes (Molenaar et al., 2012; Dyberg et al., 2017). More recent data indicate an accumulation of gene mutations in recurrent and relapsed neuroblastomas and the presence of frequent inter- and intra-tumorigenic genetic heterogeneity in individual patients which further add complexity to the molecular pathogenesis of the disease (Schleiermacher et al., 2014; Eleveld et al., 2015; Schramm et al., 2015; Braekeveldt et al., 2018).

Genome-wide association studies (GWAS) further add to the heterogeneity of the genetic landscape observed in neuroblastoma since it has been shown that there are at least a dozen highly significant polymorphic alleles that can influence the formation of neuroblastoma (Bosse and Maris, 2016). Although, each association has modest individual effect on disease initiation, multiple associations can cooperate within a patient to promote tumorigenesis. Some of the GWAS-defined neuroblastoma susceptibility genes which include CASC15, BRCA1-associated RING domain protein 1 (BARD1), LMO1, DUSP12, DDX4, IL31RA, HSD17B12, HACE1, LIN28B, and $N E F L$ have been shown to display oncogenic or tumor suppressive functions in established disease (Maris et al., 2008; Capasso et al., 2009, 2013, 2014; Diskin et al., 2009; Wang et al., 2011; Bosse et al., 2012; Pandey et al., 2014; Oldridge et al., 2015; Russell et al., 2015). Polymorphic alleles within the lin28 homolog B (LIN28B) locus have been linked to neuroblastoma development and deregulated expression of $L I N 28 B$ induces expression of MycN (Diskin et al., 2012; Molenaar et al., 2012). Lin28B also regulates microRNA (miRNA) biogenesis through depletion of the Let-7 family of miRNAs and modulate the activity of the nuclear GTP-binding protein RAN and the stability of Aurora A kinase (AURKA; Schnepp et al., 2015). This suggests that Lin28B-Ran-Aurora A kinase signaling can drive neuroblastoma tumorigenesis and that this pathway could be used as a therapeutic target (Matthay et al., 2016). Another polymorphic locus that has been strongly associated with neuroblastoma and poor prognosis is BARD1 located at chromosome $2 \mathrm{q} 35$. Fine mapping of BARD1 using GWAS identified a variant located in the canonical promoter region of $B A R D 1$ altering the binding site of the transcription factor HSF1 and correlated with low expression of full-length Bard1. Low expression of Bard1 induces proliferation and invasion of neuroblastoma cells indicating that Bard1 has a tumor suppressor function in neuroblastoma (Cimmino et al., 2018).

GWAS has also identified a locus at chromosome 6p22.3 harboring single nucleotide polymorphisms (SNPs) associated with increased risk of neuroblastoma in particular high-risk neuroblastomas (Maris et al., 2008; Russell et al., 2015). These SNPs at the 6p22.3 locus are located in the intron regions of a long noncoding RNA (lncRNA) gene CASC15 and in NBAT1 encoding a lncRNA-transcribed antisense to
CASC15 (Pandey et al., 2014). Recent data shows that CASC15 and NBAT1 promote differentiation by interactions with $S O X 9$ and USP36, located on chromosome $17 \mathrm{q}$ that is frequently gained in high-risk neuroblastomas. Lack of these lncRNAs at 6 p22.3 could lead to accumulation of undifferentiated cells within the neural crest and tumorigenesis (Mondal et al., 2018).

Taken together the molecular heterogeneity observed in neuroblastoma represent clinical challenges since tumors that seemingly are phenotypically and morphological very similar will have completely different responses to treatment depending on the molecular landscape of the tumor. This proposes that neuroblastoma patients in general and specifically those belonging to the high-risk groups should undergo careful examination to elucidate the molecular make-up of the tumor and that the treatments are designed to target the molecular aberrations detected in the individual tumor samples as a supplement to the current conventional therapies (Johnsen et al., 2018).

\section{CANDIDATE FACTORS WITHIN THE NEURAL CREST LINKED TO NEUROBLASTOMA DEVELOPMENT}

Although many molecular prognostic factors have been described in neuroblastoma only activating ALK mutations and MYCN overexpression have been proven to be de novo oncogenic drivers as mutation or overexpression of these molecules give rise to neuroblastoma in genetically engineered mouse models (Weiss et al., 1997; Heukamp et al., 2012). Mice with targeted expression of Lin28b to sympathetic adrenergic lineage cells also develop neuroblastoma. However, the tumor development in this mouse model is induced by Lin $28 \mathrm{~B}$ mediated downregulation of Let-7 resulting in overexpression of MycN protein (Molenaar et al., 2012).

\section{MYCN as an Oncogenic Driver in Neuroblastoma}

High expression of $\mathrm{MycN}$ is detected in the early post-migratory neural crest (Figure 1) and is important for regulation of ventral migration and expansion of cells within the neural crest during normal murine sympathoadrenal development (Zimmerman et al., 1986). In differentiating sympathetic neurons, the levels of $\mathrm{MycN}$ is gradually reduced suggesting that sympathoadrenal maturation is independent of $\mathrm{MycN}$ expression (Zimmerman et al., 1986; Wartiovaara et al., 2002; Hansford et al., 2004). Sympathoadrenal precursor cells maturates into neural or chromaffin cells and it is thought that preneoplastic lesions that can develop into neuroblastoma occur in sympathoadrenal precursor cells that not have received or responded to signals that determine the neuronal or chromaffin cell fate (Zimmerman et al., 1986; Marshall et al., 2014). Studies in zebrafish have shown that forced $\mathrm{MycN}$ expression in sympathoadrenal precursor cells blocks the development of chromaffin cells leading to the development of neuroblastoma (Zhu et al., 2012). During sympathoadrenal development an excess of precursor cells are produced that during the final normal maturation stages 


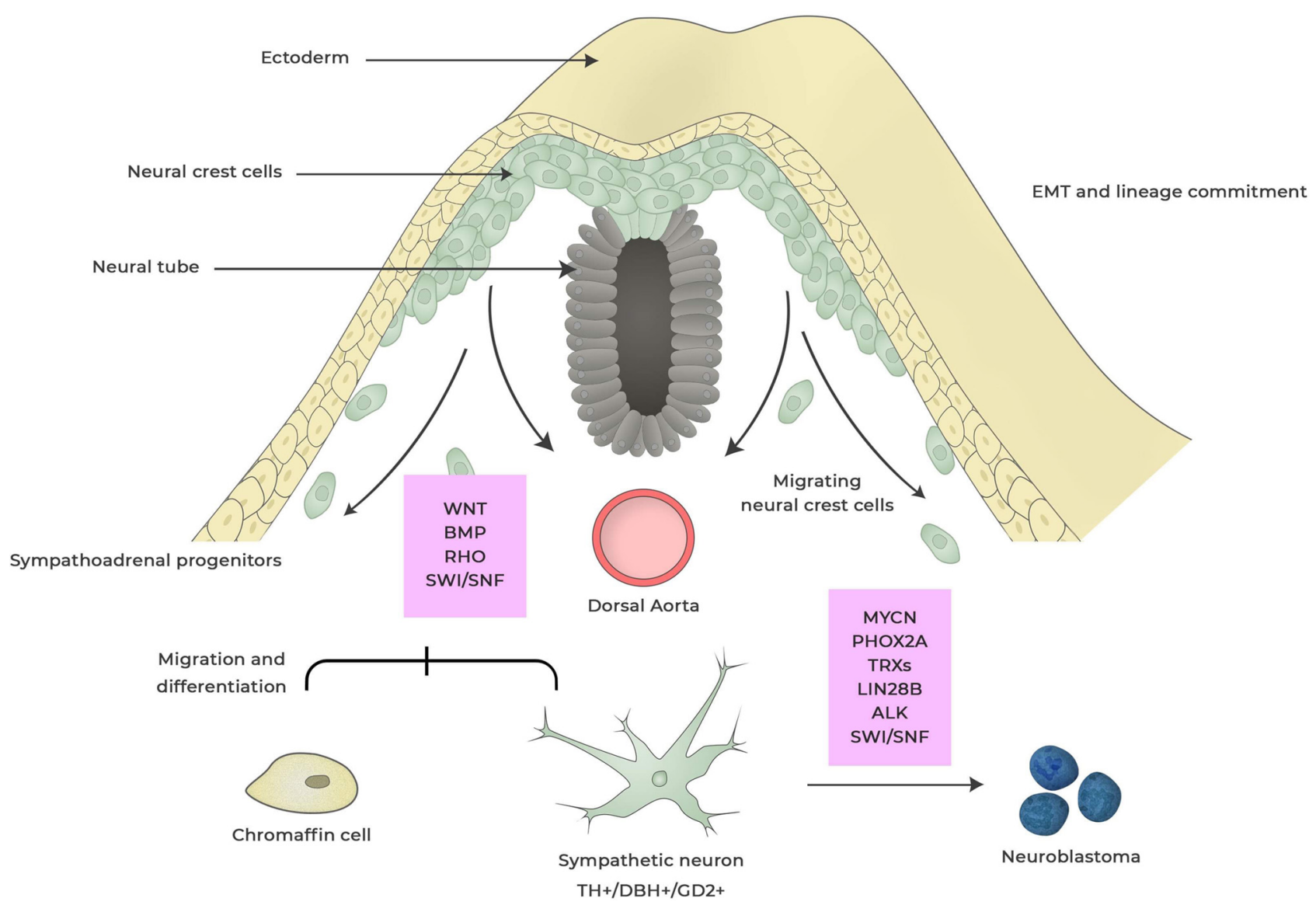

FIGURE 1 | Neuroblastoma development from neural crest. During embryogenesis cells within the neural crest undergo epithelial-to-mesenchymal transition (EMT) enabling cells to delaminate, migrate and differentiate into a wide range of cell types that contributes to anatomical structures within the organism. This process is regulated by a complex set of external signaling, activation of transcriptional programs and epigenetic events. Dysregulation of factors involved in this process can induce changes in cell specification and deregulated-migration and -cell differentiation giving rise to hyperneoplastic lesions that eventually can result in neuroblastoma. These events can occur during different stages of neural crest maturation and factors that are thought to be important for neuroblastoma development are boxed in red. Dysregulated expression of MYCN is the most powerful oncogenic driver for neuroblastoma and induces proliferation and inhibits apoptosis of sympathoadrenal lineage cells whereas LIN28B control MYCN expression via regulating Let-7 miRNA. Anaplastic lymphoma kinase (ALK) and paired-like homeobox 2B (PHOX2B) are germline mutations found in neuroblastoma. Rho signaling is crucial for the migration of neural crest cells by controlling contact inhibition of locomotion between neural crest cells. SWI/SNF complexes are tumor suppressors that for coordinate diverse chromatin alterations which influences the transcriptional output, DNA replication and repair.

undergo controlled apoptosis caused by local neural growth factor deprivation (Yuan and Yankner, 2000). MycN being a master transcription factor is involved in both cell proliferation and apoptosis (Rickman et al., 2018). Hence, persistent $\mathrm{MycN}$ expression during the maturation stages of sympathoadrenal precursors could result in blockage of apoptotic signaling and sustained proliferation eventually resulting in neuroblastoma development.

Transgenic mice where the human MYCN cDNA is placed in front of the tyrosine hydroxylase promoter (Th-MYCN) spontaneously develop neuroblastomas which are morphological and phenotypical similar to human high-risk neuroblastomas (Weiss et al., 1997; Rasmuson et al., 2012). Neuroblastoma development in this mouse model is dependent on gene dosage. All Th-MYCN mice that are homozygous $\left(M_{Y C N}{ }^{+/+}\right)$ will develop tumors 4.0-6.9 weeks of age whereas $50 \%$ of the hemizygous mice $\left(\mathrm{MYCN}^{+/-}\right)$develop tumors at 5.6-19 weeks of age (Rasmuson et al., 2012). More recent, a refined genetically engineered mouse model with Creconditional induction of $M Y C N$ in dopamine $\beta$-hydroxylaseexpressing cells termed LSL-MYCN;Dbh-iCre was shown to give rise to clinically relevant neuroblastomas in $75 \%$ of the mice (Althoff et al., 2015). Furthermore, overexpression of MYCN in primary neural crest cells result in neuroblastoma formation when these cells are transduced back into mice (Olsen et al., 2017). Also, ectopic expression of MYCN in the neural crest of zebrafish results in neuroblastoma development (Zhu et al., 2012). Together these data strongly suggest that increased and sustained expression of $\mathrm{MycN}$ in cells within the neural crest is sufficient for neuroblastoma development and establish $M Y C N$ as a major oncogenic driver in neuroblastoma. 


\section{LIN28B as an Inducer of Neuroblastoma}

The RNA binding proteins Lin28B specifically target Let-7 miRNAs by binding to the terminal loop or the pre-element region of pre-miRNAs (Newman et al., 2008; Rybak et al., 2008; Viswanathan et al., 2008). This prevents Drosha-mediated cleavage and maturation of the Let-7 pre-miRNA by the microprocessor complex (Piskounova et al., 2011). During embryogenesis Lin28B regulates the expression of Let-7 and control the developmental timing and proliferation during neural crest linage commitment (Figure 1; Rybak et al., 2008). Lin28B has also been shown to be important for the maintenance of stemness during embryonic development (Yu et al., 2007). Together these functions of Lin28B in the neural crest may result in maintenance of an undifferentiated phenotype (Rybak et al., 2008; Molenaar et al., 2012; Marshall et al., 2014). Lin28B-mediated downregulation of Let-7 miRNAs increases $\mathrm{MycN}$ expression and targeted ectopic expression of Lin28B in mouse neural crest cells results in $\mathrm{MycN}$-driven neuroblastoma (Molenaar et al., 2012). Lin28B indirect regulation of $\mathrm{MycN}$ expression by downregulation of Let-7 pre-miRNAs correspond well with a model that neuroblastoma is initiated by aberrant regulation of key developmental proteins (Marshall et al., 2014).

\section{ALK Mutations as Accelerators of Neuroblastoma Development}

More than 35 different mutations in ALK have been reported in neuroblastoma (Hallberg and Palmer, 2016). The majority of the mutations are point mutations most frequently detected in one of three hotspot residues in the kinase domain: F1174, F1245 and R1275 resulting in Alk activation (Bresler et al., 2014; Hallberg and Palmer, 2016). During mouse embryogenesis Alk is highly expressed in the developing nervous system, a pattern which is recapitulated in chicken where high expression of Alk is found in a subset of spinal motor neurons, the sympathetic ganglia and dorsal root ganglia (Figure 1; Iwahara et al., 1997; Hurley et al., 2006; Vernersson et al., 2006; Palmer et al., 2009). Enhanced proliferation of sympathetic neurons and enlargement of the sympathetic ganglion is evident in mice expressing mutant Alk (Cazes et al., 2014). ALK has also been shown to signal trough Midkine (neurite growth promoting factor-2; NEGF-2) which could be important for proliferation of the sympathoadrenal lineage during development (Reiff et al., 2011). This together with the fact that Alk mediates signaling via the JAK/STAT, RAS/MAPK, PI3K and PLC $\gamma$ pathways (Palmer et al., 2009), some of which have important functions during the development of the peripheral nervous system suggest that aberrant Alk activation plays a major role in processes leading to cellular transformation within the neural crest.

Gain-of-function mutation of $\mathrm{ALK}^{F 1174 F}$ can induce neuroblastoma in mice if $\mathrm{ALK}^{F 1174 F}$ is under control of the dopamine- $\beta$-hydroxylase $(D b h)$ promoter but require high Mycn expression in order to develop neuroblastoma when $\mathrm{ALK}^{F 1174 F}$ expression is controlled by the Th promoter in both mice and zebrafish (Weiss et al., 1997; Berry et al., 2012; Zhu et al., 2012). Also, the tumor penetrance in $d b h$ :
$\mathrm{ALK}^{\mathrm{F} 1174 F}$ mice is less efficient with $40 \%$ of the mice having neuroblastoma at 50 weeks of age, compared to Th-MYCN transgenic mice (Weiss et al., 1997; Rasmuson et al., 2012). The reasons for this discrepancy in tumor penetrance between Th- and Dbh-ALK ${ }^{F 1174 F}$ mice are not currently understood (Matthay et al., 2016). Also, Alk ${ }^{R 1279 Q}$ and $A l k^{F 1178 L}$ knock-in mouse models did not develop tumors but both Alk mutations accelerated neuroblastoma development and increased the tumor penetrance when $A l k^{R 1279 Q}$ or $A l k^{F 1178 L}$ knock-in mice were crossed with Th-MYCN mice (Cazes et al., 2014). Together these results suggest that $A L K$ is an accelerator and require other genetic insults in order to develop neuroblastoma.

\section{POTENTIAL FACTORS FOR NEUROBLASTOMA TUMORIGENESIS}

The recent development of high-throughput techniques for analyzing genomic DNA, RNA and epigenetic profiling have given valuable information on the molecular landscape of neuroblastoma and guidance to factors that are important for the initiation, development and progression of neuroblastoma from cells within the neural crest.

\section{Mutations of Genes Involved in the Epithelial-to-Mesenchymal Transition During the Migration of Neural Crest Cells as Potential Factors for Neuroblastoma}

A coordinated set of signals mainly derived from Wingless (Wnt), bone morphogenetic protein (BMP) and fibroblast growth factor (FGF) are required to initiate migration of neural crest cells by acquiring cell motility through epithelial-mesenchymal transition (EMT, Figure 1; Goldstein et al., 2005). The non-canonical Wnt-planar cell polarity (PCP) signaling cascade is fundamental for the mobilization and initiation of migration of neural crest cells by controlling contact inhibition of locomotion between cells within the neural crest. PCP proteins are controlling the activity of Rho GTPases locally by activating or inhibiting RhoA and Rac1, resulting in cells migrating away from each other upon collision (Figure 1; Sebbagh and Borg, 2014). The activation of Rho signaling results in the activation of downstream serine/threonine kinases called Rho-Associated Coiled-Coil Containing Protein Kinases, ROCK1 and ROCK2 (Anastas and Moon, 2012). ROCK1 and ROCK2 phosphorylate downstream substrates, mainly myosin light chain (MLC) and LIMK1/2, which control several cellular functions predominately through rearrangement of the actin cytoskeleton (Riento and Ridley, 2003; Hahmann and Schroeter, 2010). Genes associated with Rho/Rac signaling are frequently mutated in neuroblastoma and high ROCK2 expression correspond to poor prognosis (Molenaar et al., 2012; Dyberg et al., 2017). Also, mutations of Rho GTPase genes have been detected in low frequencies in various other cancers (Alan and Lundquist, 2013). Interestingly, recurrent somatic oncogenic driver mutations of Racl have been identified in 5\%-9\% of tumor DNA from patients with melanoma which similar to neuroblastoma also originates from 
cells within the neural crest (Berger et al., 2012; Krauthammer et al., 2012). This suggests that the mutations of Rho GTPases and related genes seen in neuroblastoma and melanoma are obtained during migration and differentiation of neural crest cells. The importance of the different mutations of Rho GTPases and associated genes in neuroblastoma is not known. The majority of these mutations have the potential to activate RhoA, inhibit Rac1 (Molenaar et al., 2012) and increase the activity of ROCK proteins (Dyberg et al., 2017). As Rho signaling is highly activated during the initiation and migration of neural crest cells, deregulated Rho/Rac1 signaling could represent an oncogenic hit during neuroblastoma development. Also, RhoA, Rac1 and Cdc42 have been implicated in both Eph/ephrin internalization and signaling. Eph/ephrin signaling plays essential roles during migration of neural crest cells, such as cytoskeleton remodeling and axon guidance but also stimulate angiogenesis and tissue separation (Baker and Antin, 2003; Xu and Wilkinson, 2013; Wislet et al., 2018). High expression levels of Ephb6 and its ligand ephrin-B2 and ephrin-B3 is associated with low-stage neuroblastoma (Tang et al., 2000). Finally, high expression of the basic-loop-helix transcription factor NeuroD1 is associated with poor prognosis in patients with neuroblastoma and NeuroD1 was found to be highly expressed in hyperplastic regions consisting of neuroblasts in the celiac sympathetic ganglion of 2 weeks old $T h-M y c N$ mice developing neuroblastoma (Huang et al., 2011). Knockdown experiments using shRNA directed against NeuroD1 inhibited the motility of neuroblastoma cells which was associated with induction of Slit2 expression (Huang et al., 2011). Slit proteins (Slit1-Slit3) are extracellular matrix glycoproteins that upon binding to the repulsive guidance receptor Roundabout (Robo1-Robo4) family regulate migration of neural crest cells (Wong et al., 2001). The Slit-Robo GTPase-activating proteins (srGAPs) are Slit-Robo effector proteins that regulate the activity of RhoGTPase family members and are important for proper migration of neural crest cells (Wong et al., 2001; Blockus and Chédotal, 2016).

\section{Mutations of Genes Guiding Neural Crest Lineage Commitment as Inducers of Neuroblastoma}

During embryogenesis the differentiation of sympathetic neurons in the neural crest is induced by members of the family of BMPs such as BMP-2, BMP-4 and BMP-7 (Figure 1) expressed by smooth muscle cells of the dorsal aorta (Varley et al., 1995; Reissmann et al., 1996; Shah et al., 1996; Varley and Maxwell, 1996). BMPs induce a differentiation in sympathetic neural precursors by controlling a set of transcription factors including Phox2b, Phox2a, Ascl1, Insm1, Hand2, Gata2/3, Sox4 and Sox11 (Howard et al., 2000; Tsarovina et al., 2004; Rohrer, 2011). In this transcriptional network PHOX2B (Figure 1) has been identified as a master gene of autonomic neuron development since Phox $2 b$ knockout in mice results in the absence of the entire peripheral autonomic nervous system (Pattyn et al., 1999). Heterozygous germline mutations as well as somatic mutations of $P H O X 2 B$ are present in a subset of neuroblastomas. These mutations are often clinically presented in combination with the neural crest disorders Hirschsprung disease and congenital hypoventilation syndrome highlighting the connection between neuroblastoma and defective neural crest development. Mutation within $P H O X 2 B$ blocks the transcriptional network responsible for the differentiation of sympathetic neurons and allows continuous proliferation of neural precursors cells (Pattyn et al., 1999; Reiff et al., 2010) which potentially could result in the development of pre-neoplastic lesions within the developing neural crest.

\section{Chromatin Remodeling Molecules as Factors for Neuroblastoma Development}

Sporadic $\alpha$-thalassaemia/mental retardation syndrome $X$ linked $(A T R X)$ mutations have been detected in a subset of neuroblastoma patients mainly in children older than 18 months having poor prognosis (Cheung et al., 2012). ATRX encodes a SWI/SNF chromatin-remodeling ATP-dependent helicase (Figure 1) that is included in ATP-dependent chromatin remodeling complexes which are responsible for reorganization of the nucleosome to make DNA accessible during transcription, replication and DNA repair (Tang et al., 2010). ATRX mutations are prevalent in X-linked mental retardation (XLMR) and $\alpha$-thalassemia syndromes. However, no increase in neuroblastoma incidence has been observed in children with XLMR suggesting that ATRX mutations alone are not sufficient to induce neoplasia (Cheung and Dyer, 2013). Atrx being a part of SWI/SNF chromosomal remodeling complexes which are important for guiding transcription and genome integrity as well as being associated to the recombination based alternative lengthening of telomerase pathway suggest that Atrx may have important functions in cellular transformation.

ARID1A and ARID1B are both members of the SWI/SNF transcriptional complex (Wang et al., 2004). SWI/SNF containing Arid1A was recently shown to be essential for neural crest development (Figure 1; Chandler and Magnuson, 2016). Homozygous loss of Arid1A results in embryonic lethality in mice, with mutant embryos succumbing to heart defects whereas heterozygous loss of Arid1A in the neural crest result in craniofacial defects in adult mice (Chandler and Magnuson, 2016). High frequency of ARID1A mutations have been reported in Coffin-Siris syndrome (CSS) a congenital disorder associated with intellectual disability or developmental delay, hypoplastic fifth fingernails, and patterning defects in the head and heart (Kosho et al., 2014). Like CSS, ARID-1A and -1B mutations are also found in a subset of neuroblastoma (Sausen et al., 2013). In addition, mutations in the histone acetyl transferase (HAC) genes EP300 and CREBBP, the SWI2/SNF2 family member TTF2 gene, the histone demethylase gene KDM5A, the chromatin remodeling zinc finger gene IKZF1 and ATRX, described above, has also been reported in neuroblastoma (Sausen et al., 2013). SWI/SNF chromatin remodeling complexes are fundamental for coordinating a diverse set of chromatin alterations which influences the transcriptional output, DNA replication and repair (Tang et al., 2010). Genes encoding subunits of SWI/SNF complexes are mutated in over $20 \%$ of human 
cancers (St Pierre and Kadoch, 2017). The majority of these mutations of subunits within the SWI/SNF complexes results in loss of protein expression implicating SWI/SNF subunits as tumor suppressors (St Pierre and Kadoch, 2017). Although the effect $A R I D 1 A / 1 B$ mutations found in neuroblastoma need to be functionally analyzed, the fact that Arid-1A and -1B are part of the SWI/SNF tumor suppressor complexes suggest that these factors are important for deregulation of neural crest cells and neuroblastoma development.

\section{BARD1 as a Potential Factor for Neuroblastoma}

BRCA1 Associated RING Domain 1 (BARD1) encodes a protein which interacts with the N-terminal region of Brcal. Recent data indicates that different splice variants transcribed from the BARD1 gene can have either tumor suppressing or oncogenic functions. Full-length Bard1 proteins act as tumor suppressor with or without interaction with Brcal whereas different splice variants detected in various cancers have oncogenic properties (Cimmino et al., 2017). As described above, GWAS identified SNPs within the BARD1 locus that is strongly associated with neuroblastoma (Bosse and Maris, 2016). SNPs associated with high risk of neuroblastoma expressed high levels of $B A R D 1$ splice variants whereas no correlation to neuroblastoma was detected in SNPs expressing full-length Bard1 (Capasso et al., 2013). One isoform, called Bard $1 \beta$, has been shown to be important for neuroblastoma cell survival and to induce neoplastic transformation when overexpressed in murine fibroblasts (Bosse et al., 2012). The precise expression pattern and function of BARD1 and its splice variants during neural crest development has not yet been described. However, different copy number variants of the $B A R D 1$ locus have been associated with congenital heart defects, aortic narrowing and tetralogy of Fallot all of which, as for neuroblastoma, have tissues that are derived from neural crest cells (Silversides et al., 2012). Through its interaction with Brcal, Bard1 has a pivotal role in DNA damage repair, ubiquitination, and transcriptional regulation to maintain genomic stability and deregulated expression of full-length Bard1 by SNPs splice variants located in the BARD1 locus may have important implications for neuroblastoma development.

\section{NEUROBLASTOMA AS AN EMBRYONAL TUMOR}

Several lines of both clinical and experimental evidences suggest that neuroblastoma originates from dysregulation of cellular processes during early embryogenesis. As described in details above, gene mutations or amplifications as well as dysregulation of signal transduction pathways and epigenetic changes during neural crest development can induce preneoplastic lesions and eventually neuroblastoma. Studies done in Th-MYCN transgenic mice shows an accumulation of a population of small, blue round cells in the paravertebral ganglia from embryonic day 14. This population of cells called neuroblast hyperplasia later develops into neuroblastoma observed in $100 \%$ of the MYCN homozygous mice from postnatal week 6 (Hansford et al., 2004). Similar observations were also evident in the $\operatorname{Tg}(d \beta h: E G F P-M Y C N)$ zebrafish model (Zhu et al., 2012). In humans the incidence of subclinical neuroblastomas is much higher than the frequency of clinical cases. Autopsies of sympathoadrenal tissues of infant whose cause of death were non-cancerous showed that the occurrence of precancerous neuroblasts was 40 times higher than the incidence of clinical disease (Beckwith and Perrin, 1963). Also, mass screening programs in Germany, France, Austria, North America and Japan during the 1990s for catecholamines in urine samples of infants found subclinical tumors at a frequency that was more than two-fold higher than the clinical incidence of neuroblastoma (Woods et al., 1996; Schilling et al., 2002). Although unsuccessful, these screening programs were initiated in order to prevent later metastatic neuroblastoma by early detection of localized tumors at infancy (Woods et al., 1996; Schilling et al., 2002).

There is one feature of neuroblastoma that is unique among human cancers and that is the propensity to spontaneously regress (Brodeur, 2018). Spontaneous regression is most evident in a specialized subgroup of infant neuroblastoma patients called $4 \mathrm{~S}$. Patients with stage $4 \mathrm{~S}$ disease are infants up to 18 months of age and usually present with small abdominal primary tumors with metastases to the liver, skin, and bone marrow (Monclair et al., 2009). Stage 4 S patients generally have very good prognosis and some undergo spontaneous regression without any treatment (D'Angio et al., 1971; Evans et al., 1971). The underlying mechanisms of the spontaneous tumor regression observed in stage $4 \mathrm{~S}$ patients have not been defined but neurotrophin deprivation, loss of telomerase activity, epigenetic regulation or immune responses have been proposed to be responsible for neuroblastoma regression (Brodeur and Bagatell, 2014). Hence, regression of stage 4 S neuroblastoma mimics features observed within the neural crest where excess neural precursors undergo apoptotic cell death at the final stage of sympathoadrenal maturation (Yuan and Yankner, 2000).

\section{Current Treatment of Neuroblastoma}

Treatment of neuroblastoma patients diverges extensively between the different risk groups. Treatment of high-risk patients involves intense induction chemotherapy regimen that includes cisplatin, vincristine, carboplatin, etoposide and cyclophosphamide (COJEC; Pearson et al., 2008; Ladenstein et al., 2017). The induction therapy is followed by surgery and myeloablative therapy combined with reinfusion of hematopoietic stem cells and local radiotherapy. Maintenance treatment includes retinoic acid aiming to differentiate the remaining tumor cells and immunotherapy using anti-GD2 together with granulocyte macrophage colony stimulating factor (GM-CSF) and interleukin-2 (IL-2; Yu et al., 2010; Ladenstein et al., 2013; Park et al., 2014; Matthay et al., 2016; Berlanga et al., 2017; Shohet and Foster, 2017).

Patients categorized to the intermediate-risk group are given milder chemotherapy continued by surgical resection of the remaining tumor mass. Treatment of low-risk neuroblastomas include minimal chemotherapy and some children are cured by only surgery or no treatment caused by spontaneous tumor regression (Matthay et al., 2016; Berlanga et al., 2017; 
Shohet and Foster, 2017). Detailed descriptions of neuroblastoma treatment for different risk groups, and discussions of current clinical trials for neuroblastoma patients as well as investigational drugs depicting promising preclinical effects on neuroblastoma have recently been described by us and others (Matthay et al., 2016; Berlanga et al., 2017; Esposito et al., 2017; Moreno et al., 2017; Shohet and Foster, 2017; Whittle et al., 2017; Fletcher et al., 2018; Johnsen et al., 2018).

\section{CONCLUSION}

Neuroblastoma can be regarded as neurodevelopmental disease originating from cells within the neural crest. As our detailed understanding of the complex network of interand intra-cellular communications within the neural crest are being resolved more knowledge of the cellular origin of neuroblastoma and mechanisms for neuroblastoma initiation will be understood. There is also a need to develop new preclinical models that mimic the genetic and chromosomal features seen in neuroblastoma. This has proven to be complicated since the majority of neuroblastoma present with very few gene mutations in which only a few have a proven oncogenic driver function. High-risk neuroblastomas usually have segmental chromosomal gain or losses. We currently have no knowledge on how these chromosomal aberrations arise within the pre-malignant cells or in neural crest-derived cells. These chromosomal gain or losses are demanding to study in preclinical in vivo models since the chromosomal make-up between mice and men are different. Neuroblastoma is still

\section{REFERENCES}

Acheson, A., Conover, J. C., Fandl, J. P., DeChiara, T. M., Russell, M., Thadani, A., et al. (1995). A BDNF autocrine loop in adult sensory neurons prevents cell death. Nature 374, 450-453. doi: 10.1038/374450a0

Alan, J. K., and Lundquist, E. A. (2013). Mutationally activated Rho GTPases in cancer. Small GTPases 4, 159-163. doi: 10.4161/sgtp.26530

Althoff, K., Beckers, A., Bell, E., Nortmeyer, M., Thor, T., Sprussel, A., et al. (2015). A cre-conditional MYCN-driven neuroblastoma mouse model as an improved tool for preclinical studies. Oncogene 34, 3357-3368. doi: 10.1038/onc. 2014.269

Ambros, P. F., Ambros, I. M., Brodeur, G. M., Haber, M., Khan, J., Nakagawara, A., et al. (2009). International consensus for neuroblastoma molecular diagnostics: report from the international neuroblastoma risk group (INRG) biology committee. Br. J. Cancer 100, 1471-1482. doi: 10.1038/sj.bjc.6605014

Anastas, J. N., and Moon, R. T. (2012). WNT signalling pathways as therapeutic targets in cancer. Nat. Rev. Cancer 13, 11-26. doi: 10.1038/nrc3419

Baker, R. K., and Antin, P. B. (2003). Ephs and ephrins during early stages of chick embryogenesis. Dev. Dyn. 228, 128-142. doi: 10.1002/dvdy.10354

Beckwith, J. B., and Perrin, E. V. (1963). In situ neuroblastomas: a contribution to the natural history of neural crest tumors. Am. J. Pathol. 43, 1089-1104.

Berger, M. F., Hodis, E., Heffernan, T. P., Deribe, Y. L., Lawrence, M. S., Protopopov, A., et al. (2012). Melanoma genome sequencing reveals frequent PREX2 mutations. Nature 485, 502-506. doi: 10.1038/nature11071

Berlanga, P., Cañete, A., and Castel, V. (2017). Advances in emerging drugs for the treatment of neuroblastoma. Expert Opin. Emerg. Drugs 22, 63-75. doi: 10.1080/14728214.2017.1294159

Berry, T., Luther, W., Bhatnagar, N., Jamin, Y., Poon, E., Sanda, T., et al. (2012). The ALK(F1174L) mutation potentiates the oncogenic activity of MYCN in neuroblastoma. Cancer Cell 22, 117-130. doi: 10.1016/j.ccr.2012.06.001

Blockus, H., and Chédotal, A. (2016). Slit-Robo signaling. Development 143, 3037-3044. one of the most deadliest malignancies of childhood and we will need to refine current treatment protocols, include more targeted therapies, both pharmacologically and cellular which reflect the molecular landscape of individual tumors and to continue analyzing the influence of cells within the tumor microenvironment to search for novel therapy options. In order to accomplish this, we will need to develop more preclinical models that mimic the chromosomal and genetic landscape seen in neuroblastoma and to target these aberrations to specific cells within the neural crest.

\section{AUTHOR CONTRIBUTIONS}

JJ, CD and MW wrote the manuscript.

\section{FUNDING}

This work was supported with grants from the Swedish Childhood Cancer Fund (Barncancerfonden), the Swedish Cancer Society (Cancerfonden), the Swedish Foundation for Strategic Research (Stiftelsen för Strategisk Forskning; www.nnbcr.se), The Cancer Research Foundations of Radiumhemmet (Radiumhemmets Forskningsfonder), Magnus Bergvalls stiftelse and Märta and Gunnar V Philipson Foundation.

\section{ACKNOWLEDGMENTS}

We thank Helene Westerberg for graphical design of the figure.

Bosse, K. R., Diskin, S. J., Cole, K. A., Wood, A. C., Schnepp, R. W., Norris, G., et al (2012). Common variation at BARD1 results in the expression of an oncogenic isoform that influences neuroblastoma susceptibility and oncogenicity. Cancer Res. 72, 2068-2078. doi: 10.1158/0008-5472.can-11-3703

Bosse, K. R., and Maris, J. M. (2016). Advances in the translational genomics of neuroblastoma: from improving risk stratification and revealing novel biology to identifying actionable genomic alterations. Cancer 122, 20-33. doi: $10.1002 / \mathrm{cncr} .29706$

Braekeveldt, N., von Stedingk, K., Fransson, S., Martinez-Monleon, A., Lindgren, D., Axelson, H., et al. (2018). Patient-derived xenograft models reveal intratumor heterogeneity and temporal stability in neuroblastoma. Cancer Res. 78, 5958-5969. doi: 10.1158/0008-5472.CAN-18-0527

Bresler, S. C., Weiser, D. A., Huwe, P. J., Park, J. H., Krytska, K., Ryles, H., et al. (2014). ALK mutations confer differential oncogenic activation and sensitivity to ALK inhibition therapy in neuroblastoma. Cancer Cell 26, 682-694. doi: 10.1016/j.ccell.2014.09.019

Brodeur, G. M. (2003). Neuroblastoma: biological insights into a clinical enigma. Nat. Rev. Cancer 3, 203-216. doi: 10.1038/nrc1014

Brodeur, G. M. (2018). Spontaneous regression of neuroblastoma. Cell Tissue Res. 372, 277-286. doi: 10.1007/s00441-017-2761-2

Brodeur, G. M., and Bagatell, R. (2014). Mechanisms of neuroblastoma regression. Nat. Rev. Clin. Oncol. 11, 704-713. doi: 10.1038/nrclinonc.2014.168

Brodeur, G. M., Minturn, J. E., Ho, R., Simpson, A. M., Iyer, R., Varela, C. R., et al. (2009). Trk receptor expression and inhibition in neuroblastomas. Clin. Cancer Res. 15, 3244-3250. doi: 10.1158/1078-0432.ccr-08-1815

Brodeur, G. M., Nakagawara, A., Yamashiro, D. J., Ikegaki, N., Liu, X. G., Azar, C. G., et al. (1997). Expression of TrkA, TrkB and TrkC in human neuroblastomas. J. Neurooncol. 31, 49-55. doi: 10.1023/A:10057293 29526

Capasso, M., Devoto, M., Hou, C., Asgharzadeh, S., Glessner, J. T., Attiyeh, E. F., et al. (2009). Common variations in BARD1 influence susceptibility to high-risk neuroblastoma. Nat. Genet. 41, 718-723. doi: 10.1038/ng.374 
Capasso, M., Diskin, S., Cimmino, F., Acierno, G., Totaro, F., Petrosino, G., et al. (2014). Common genetic variants in NEFL influence gene expression and neuroblastoma risk. Cancer Res. 74, 6913-6924. doi: 10.1158/0008-5472.can14-0431

Capasso, M., Diskin, S. J., Totaro, F., Longo, L., De Mariano, M., Russo, R., et al. (2013). Replication of GWAS-identified neuroblastoma risk loci strengthens the role of BARD1 and affirms the cumulative effect of genetic variations on disease susceptibility. Carcinogenesis 34, 605-611. doi: 10.1093/carcin/bgs380

Carén, H., Kryh, H., Nethander, M., Sjöberg, R. M., Träger, C., Nilsson, S., et al. (2010). High-risk neuroblastoma tumors with 11q-deletion display a poor prognostic, chromosome instability phenotype with later onset. Proc. Natl. Acad. Sci. U S A 107, 4323-4328. doi: 10.1073/pnas.0910684107

Cazes, A., Lopez-Delisle, L., Tsarovina, K., Pierre-Eugene, C., De Preter, K., Peuchmaur, M., et al. (2014). Activated Alk triggers prolonged neurogenesis and Ret upregulation providing a therapeutic target in ALK-mutated neuroblastoma. Oncotarget 5, 2688-2702. doi: 10.18632/oncotarget.1883

Chandler, R. L., and Magnuson, T. (2016). The SWI/SNF BAF-A complex is essential for neural crest development. Dev. Biol. 411, 15-24. doi: 10.1016/j. ydbio.2016.01.015

Cheung, N. K., and Dyer, M. A. (2013). Neuroblastoma: developmental biology, cancer genomics and immunotherapy. Nat. Rev. Cancer 13, 397-411. doi: $10.1038 / \mathrm{nrc} 3526$

Cheung, N. K., Zhang, J., Lu, C., Parker, M., Bahrami, A., Tickoo, S. K., et al. (2012). Association of age at diagnosis and genetic mutations in patients with neuroblastoma. JAMA 307, 1062-1071. doi: 10.1001/jama.2012.228

Cimmino, F., Avitabile, M., Diskin, S. J., Vaksman, Z., Pignataro, P., Formicola, D., et al. (2018). Fine mapping of $2 q 35$ high-risk neuroblastoma locus reveals independent functional risk variants and suggests full-length BARD1 as tumorsuppressor. Int. J. Cancer 143, 2828-2837. doi: 10.1002/ijc.31822

Cimmino, F., Formicola, D., and Capasso, M. (2017). Dualistic role of BARD1 in cancer. Genes 8:E375. doi: 10.3390/genes8120375

D'Angio, G. J., Evans, A. E., and Koop, C. E. (1971). Special pattern of widespread neuroblastoma with a favourable prognosis. Lancet 1, 1046-1049. doi: 10.1016/s0140-6736(71)91606-0

Diskin, S. J., Capasso, M., Schnepp, R. W., Cole, K. A., Attiyeh, E. F., Hou, C., et al. (2012). Common variation at 6q16 within HACE1 and LIN28B influences susceptibility to neuroblastoma. Nat. Genet. 44, 1126-1130. doi: 10.1038/ng. 2387

Diskin, S. J., Hou, C., Glessner, J. T., Attiyeh, E. F., Laudenslager, M., Bosse, K., et al. (2009). Copy number variation at 1q21.1 associated with neuroblastoma. Nature 459, 987-991. doi: 10.1038/nature08035

Dyberg, C., Fransson, S., Andonova, T., Sveinbjornsson, B., LannerholmPalm, J., Olsen, T. K., et al. (2017). Rho-associated kinase is a therapeutic target in neuroblastoma. Proc. Natl. Acad. Sci. U S A 114, E6603-E6612. doi: 10.1073/pnas.1706011114

Eleveld, T. F., Oldridge, D. A., Bernard, V., Koster, J., Colmet Daage, L., Diskin, S. J., et al. (2015). Relapsed neuroblastomas show frequent RAS-MAPK pathway mutations. Nat. Genet. 47, 864-871. doi: 10.1038/ng.3333

Esposito, M. R., Aveic, S., Seydel, A., and Tonini, G. P. (2017). Neuroblastoma treatment in the post-genomic era. J. Biomed. Sci. 24:14. doi: 10.1186/s12929017-0319-y

Evans, A. E., D’Angio, G. J., and Randolph, J. (1971). A proposed staging for children with neuroblastoma. Children's cancer study group A. Cancer 27, 374-378. doi: 10.1002/1097-0142(197102)27:2<374::aid-cncr2820270221>3.0. co; 2 -g

Fletcher, J. I., Ziegler, D. S., Trahair, T. N., Marshall, G. M., Haber, M., and Norris, M. D. (2018). Too many targets, not enough patients: rethinking neuroblastoma clinical trials. Nat. Rev. Cancer 18, 389-400. doi: 10.1038/s41568-018-0003-x

Goldstein, A. M., Brewer, K. C., Doyle, A. M., Nagy, N., and Roberts, D. J. (2005). BMP signaling is necessary for neural crest cell migration and ganglion formation in the enteric nervous system. Mech. Dev. 122, 821-833. doi: 10.1016/j.mod.2005.03.003

Hahmann, C., and Schroeter, T. (2010). Rho-kinase inhibitors as therapeutics: from pan inhibition to isoform selectivity. Cell. Mol. Life Sci. 67, 171-177. doi: 10.1007/s00018-009-0189-x

Hallberg, B., and Palmer, R. H. (2016). The role of the ALK receptor in cancer biology. Ann. Oncol. 27, iii4-iii15. doi: 10.1093/annonc/mdw301
Hansford, L. M., Thomas, W. D., Keating, J. M., Burkhart, C. A., Peaston, A. E., Norris, M. D., et al. (2004). Mechanisms of embryonal tumor initiation: distinct roles for MycN expression and MYCN amplification. Proc. Natl. Acad. Sci. U S A 101, 12664-12669. doi: 10.1073/pnas.0401083101

Heukamp, L. C., Thor, T., Schramm, A., De Preter, K., Kumps, C., De Wilde, B., et al. (2012). Targeted expression of mutated ALK induces neuroblastoma in transgenic mice. Sci. Transl. Med. 4:141ra191. doi: 10.1126/scitranslmed. 3003967

Howard, M. J., Stanke, M., Schneider, C., Wu, X., and Rohrer, H. (2000). The transcription factor dHAND is a downstream effector of BMPs in sympathetic neuron specification. Development 127, 4073-4081.

Huang, P., Kishida, S., Cao, D., Murakami-Tonami, Y., Mu, P., Nakaguro, M., et al. (2011). The neuronal differentiation factor NeuroD1 downregulates the neuronal repellent factor Slit 2 expression and promotes cell motility and tumor formation of neuroblastoma. Cancer Res. 71, 2938-2948. doi: 10.1158/00085472.can-10-3524

Hurley, S. P., Clary, D. O., Copie, V., and Lefcort, F. (2006). Anaplastic lymphoma kinase is dynamically expressed on subsets of motor neurons and in the peripheral nervous system. J. Comp. Neurol. 495, 202-212. doi: 10.1002/cne. 20887

Irwin, M. S., and Park, J. R. (2015). Neuroblastoma: paradigm for precision medicine. Pediatr. Clin. North Am. 62, 225-256. doi: 10.1016/j.pcl.2014. 09.015

Iwahara, T., Fujimoto, J., Wen, D., Cupples, R., Bucay, N., Arakawa, T., et al. (1997). Molecular characterization of ALK, a receptor tyrosine kinase expressed specifically in the nervous system. Oncogene 14, 439-449. doi: 10.1038/sj.onc. 1200849

Johnsen, J. I., Dyberg, C., Fransson, S., and Wickstrom, M. (2018). Molecular mechanisms and therapeutic targets in neuroblastoma. Pharmacol. Res. 131, 164-176. doi: 10.1016/j.phrs.2018.02.023

Johnsen, J. I., Kogner, P., Albihn, A., and Henriksson, M. A. (2009). Embryonal neural tumours and cell death. Apoptosis 14, 424-438. doi: 10.1007/s10495-0090325-y

Kogner, P., Barbany, G., Dominici, C., Castello, M. A., Raschella, G., and Persson, H. (1993). Coexpression of messenger RNA for TRK protooncogene and low affinity nerve growth factor receptor in neuroblastoma with favorable prognosis. Cancer Res. 53, 2044-2050.

Kosho, T., Okamoto, N., and Coffin-Siris Syndrome International. (2014). Genotype-phenotype correlation of coffin-siris syndrome caused by mutations in SMARCB1, SMARCA4, SMARCE1 and ARID1A. Am. J. Med. Genet. C Semin. Med. Genet. 166C, 262-275. doi: 10.1002/ajmg.c.31407

Krauthammer, M., Kong, Y., Ha, B. H., Evans, P., Bacchiocchi, A., McCusker, J. P., et al. (2012). Exome sequencing identifies recurrent somatic RAC1 mutations in melanoma. Nat. Genet. 44, 1006-1014. doi: 10.1038/ng.2359

L'Abbate, A., Macchia, G., D’Addabbo, P., Lonoce, A., Tolomeo, D., Trombetta, D., et al. (2014). Genomic organization and evolution of double minutes/homogeneously staining regions with MYC amplification in human cancer. Nucleic Acids Res. 42, 9131-9145. doi: 10.1093/nar/gku590

Ladenstein, R., Potschger, U., Pearson, A. D. J., Brock, P., Luksch, R., Castel, V., et al. (2017). Busulfan and melphalan versus carboplatin, etoposide and melphalan as high-dose chemotherapy for high-risk neuroblastoma (HR-NBL1/SIOPEN): an international, randomised, multi-arm, open-label, phase 3 trial. Lancet Oncol. 18, 500-514. doi: 10.1016/s1470-2045(17) 30070-0

Ladenstein, R., Weixler, S., Baykan, B., Bleeke, M., Kunert, R., Katinger, D., et al. (2013). Ch14.18 antibody produced in CHO cells in relapsed or refractory stage 4 neuroblastoma patients: a SIOPEN phase 1 study. MAbs 5, 801-809. doi: $10.4161 /$ mabs. 25215

Lammie, G., Cheung, N., Gerald, W., Rosenblum, M., and Cordoncardo, C. (1993). Ganglioside $\operatorname{gd}(2)$ expression in the human nervous-system and in neuroblastomas-an immunohistochemical study. Int. J. Oncol. 3, 909-915. doi: 10.3892/ijo.3.5.909

London, W. B., Castleberry, R. P., Matthay, K. K., Look, A. T., Seeger, R. C., Shimada, H., et al. (2005). Evidence for an age cutoff greater than 365 days for neuroblastoma risk group stratification in the children's oncology group. J. Clin. Oncol. 23, 6459-6465. doi: 10.1200/JCO.2005.05.571

Maris, J. M. (2010). Recent advances in neuroblastoma. N. Engl. J. Med. 362, 2202-2211. doi: 10.1056/NEJMra0804577 
Maris, J. M., Mosse, Y. P., Bradfield, J. P., Hou, C., Monni, S., Scott, R. H., et al. (2008). Chromosome 6p22 locus associated with clinically aggressive neuroblastoma. N. Engl. J. Med. 358, 2585-2593. doi: 10.1056/NEJMoa0708698

Marshall, G. M., Carter, D. R., Cheung, B. B., Liu, T., Mateos, M. K., Meyerowitz, J. G., et al. (2014). The prenatal origins of cancer. Nat. Rev. Cancer 14, 277-289. doi: 10.1038/nrc3679

Matsumoto, K., Wada, R. K., Yamashiro, J. M., Kaplan, D. R., and Thiele, C. J. (1995). Expression of brain-derived neurotrophic factor and p145TrkB affects survival, differentiation and invasiveness of human neuroblastoma cells. Cancer Res. 55, 1798-1806.

Matthay, K. K., Maris, J. M., Schleiermacher, G., Nakagawara, A., Mackall, C. L., Diller, L., et al. (2016). Neuroblastoma. Nat. Rev. Dis. Primers 2:16078. doi: $10.1038 /$ nrdp. 2016.78

Matthay, K. K., Reynolds, C. P., Seeger, R. C., Shimada, H., Adkins, E. S., Haas-Kogan, D., et al. (2009). Long-term results for children with high-risk neuroblastoma treated on a randomized trial of myeloablative therapy followed by 13-cis-retinoic acid: a children's oncology group study. J. Clin. Oncol. 27, 1007-1013. doi: 10.1200/JCO.2007.13.8925

Mody, R., Naranjo, A., Van Ryn, C., Yu, A. L., London, W. B., Shulkin, B. L., et al. (2017). Irinotecan-temozolomide with temsirolimus or dinutuximab in children with refractory or relapsed neuroblastoma (COG ANBL1221): an open-label, randomised, phase 2 trial. Lancet Oncol. 18, 946-957. doi: 10.1016/s1470-2045(17)30355-8

Molenaar, J. J., Koster, J., Zwijnenburg, D. A., van Sluis, P., Valentijn, L. J., van der Ploeg, I., et al. (2012). Sequencing of neuroblastoma identifies chromothripsis and defects in neuritogenesis genes. Nature 483, 589-593. doi: 10.1038/nature10910

Monclair, T., Brodeur, G. M., Ambros, P. F., Brisse, H. J., Cecchetto, G., Holmes, K., et al. (2009). The international neuroblastoma risk group (INRG) staging system: an INRG task force report. J. Clin. Oncol. 27, 298-303. doi: $10.1200 / J C O .2008 .16 .6876$

Mondal, T., Juvvuna, P. K., Kirkeby, A., Mitra, S., Kosalai, S. T., Traxler, L., et al. (2018). Sense-Antisense IncRNA pair encoded by locus 6p22.3 determines neuroblastoma susceptibility via the USP36-CHD7-SOX9 regulatory axis. Cancer Cell 33, 417.e7-434.e7. doi: 10.1016/j.ccell.2018.01.020

Moreno, L., Caron, H., Geoerger, B., Eggert, A., Schleiermacher, G., Brock, P., et al. (2017). Accelerating drug development for neuroblastoma-new drug development strategy: an innovative therapies for children with cancer, european network for cancer research in children and adolescents and international society of paediatric oncology europe neuroblastoma project. Expert Opin. Drug Discov. 12, 801-811. doi: 10.1080/17460441.2017.13 40269

Morgenstern, D. A., London, W. B., Stephens, D., Volchenboum, S. L., Hero, B., Di Cataldo, A., et al. (2014). Metastatic neuroblastoma confined to distant lymph nodes (stage $4 \mathrm{~N}$ ) predicts outcome in patients with stage 4 disease: a study from the international neuroblastoma risk group database. J. Clin. Oncol. 32, 1228-1235. doi: 10.1200/JCO.2013.53.6342

Mossé, Y. P., Laudenslager, M., Longo, L., Cole, K. A., Wood, A., Attiyeh, E. F., et al. (2008). Identification of ALK as a major familial neuroblastoma predisposition gene. Nature 455, 930-935. doi: 10.1038/nature07261

Nakagawara, A., Arima-Nakagawara, M., Scavarda, N. J., Azar, C. G., Cantor, A. B., and Brodeur, G. M. (1993). Association between high levels of expression of the TRK gene and favorable outcome in human neuroblastoma. N. Engl. J. Med. 328, 847-854. doi: 10.1056/NEJM199303253281205

Nakagawara, A., Azar, C. G., Scavarda, N. J., and Brodeur, G. M. (1994). Expression and function of TRK-B and BDNF in human neuroblastomas. Mol. Cell. Biol. 14, 759-767. doi: 10.1128/mcb.14.1.759

Newman, M. A., Thomson, J. M., and Hammond, S. M. (2008). Lin-28 interaction with the Let-7 precursor loop mediates regulated microRNA processing. RNA 14, 1539-1549. doi: 10.1261/rna.1155108

Ohmi, Y., Ohkawa, Y., Yamauchi, Y., Tajima, O., Furukawa, K., and Furukawa, K. (2012). Essential roles of gangliosides in the formation and maintenance of membrane microdomains in brain tissues. Neurochem. Res. 37, 1185-1191. doi: 10.1007/s11064-012-0764-7

Oldridge, D. A., Wood, A. C., Weichert-Leahey, N., Crimmins, I., Sussman, R., Winter, C., et al. (2015). Genetic predisposition to neuroblastoma mediated by a LMO1 super-enhancer polymorphism. Nature 528, 418-421. doi: 10.1038/nature15540
Olsen, R. R., Otero, J. H., García-López, J., Wallace, K., Finkelstein, D., Rehg, J. E., et al. (2017). MYCN induces neuroblastoma in primary neural crest cells. Oncogene 36, 5075-5082. doi: 10.1038/onc.2017.128

Palmer, R. H., Vernersson, E., Grabbe, C., and Hallberg, B. (2009). Anaplastic lymphoma kinase: signalling in development and disease. Biochem. J. 420, 345-361. doi: 10.1042/BJ20090387

Pandey, G. K., Mitra, S., Subhash, S., Hertwig, F., Kanduri, M., Mishra, K., et al. (2014). The risk-associated long noncoding RNA NBAT-1 controls neuroblastoma progression by regulating cell proliferation and neuronal differentiation. Cancer Cell 26, 722-737. doi: 10.1016/j.ccell.2014.09.014

Park, J. R., Eggert, A., and Caron, H. (2010). Neuroblastoma: biology, prognosis and treatment. Hematol. Oncol. Clin. North Am. 24, 65-86. doi: 10.1016/j.hoc. 2009.11.011

Park, S. J., Jo, D. S., Shin, J. H., Kim, E. S., Jo, Y. K., Choi, E. S., et al. (2014). Suppression of Cpn10 increases mitochondrial fission and dysfunction in neuroblastoma cells. PLoS One 9:e112130. doi: 10.1371/journal.pone.0112130

Pattyn, A., Morin, X., Cremer, H., Goridis, C., and Brunet, J. F. (1999). The homeobox gene Phox $2 \mathrm{~b}$ is essential for the development of autonomic neural crest derivatives. Nature 399, 366-370. doi: 10.1038/20700

Pearson, A. D., Pinkerton, C. R., Lewis, I. J., Imeson, J., Ellershaw, C., and Machin, D. (2008). High-dose rapid and standard induction chemotherapy for patients aged over 1 year with stage 4 neuroblastoma: a randomised trial. Lancet Oncol. 9, 247-256. doi: 10.1016/s1470-2045(08)70069-X

Peifer, M., Hertwig, F., Roels, F., Dreidax, D., Gartlgruber, M., Menon, R., et al. (2015). Telomerase activation by genomic rearrangements in high-risk neuroblastoma. Nature 526, 700-704. doi: 10.1038/nature14980

Piskounova, E., Polytarchou, C., Thornton, J. E., LaPierre, R. J., Pothoulakis, C., Hagan, J. P., et al. (2011). Lin28A and Lin28B inhibit let-7 microRNA biogenesis by distinct mechanisms. Cell 147, 1066-1079. doi: 10.1016/j.cell. 2011.10.039

Pugh, T. J., Morozova, O., Attiyeh, E. F., Asgharzadeh, S., Wei, J. S., Auclair, D., et al. (2013). The genetic landscape of high-risk neuroblastoma. Nat. Genet. 45 , 279-284. doi: $10.1038 / \mathrm{ng} .2529$

Rasmuson, A., Segerström, L., Nethander, M., Finnman, J., Elfman, L. H., Javanmardi, N., et al. (2012). Tumor development, growth characteristics and spectrum of genetic aberrations in the TH-MYCN mouse model of neuroblastoma. PLoS One 7:e51297. doi: 10.1371/journal.pone.0051297

Reiff, T., Huber, L., Kramer, M., Delattre, O., Janoueix-Lerosey, I., and Rohrer, H. (2011). Midkine and Alk signaling in sympathetic neuron proliferation and neuroblastoma predisposition. Development 138, 4699-4708. doi: 10.1242/dev. 072157

Reiff, T., Tsarovina, K., Majdazari, A., Schmidt, M., del Pino, I., and Rohrer, H. (2010). Neuroblastoma phox $2 b$ variants stimulate proliferation and dedifferentiation of immature sympathetic neurons. J. Neurosci. 30, 905-915. doi: 10.1523/JNEUROSCI.5368-09.2010

Reissmann, E., Ernsberger, U., Francis-West, P. H., Rueger, D., Brickell, P. M., and Rohrer, H. (1996). Involvement of bone morphogenetic protein-4 and bone morphogenetic protein-7 in the differentiation of the adrenergic phenotype in developing sympathetic neurons. Development 122, 2079-2088.

Rickman, D. S., Schulte, J. H., and Eilers, M. (2018). The expanding world of NMYC-driven tumors. Cancer Discov. 8, 150-163. doi: 10.1158/2159-8290.CD17-0273

Riento, K., and Ridley, A. J. (2003). Rocks: multifunctional kinases in cell behaviour. Nat. Rev. Mol. Cell Biol. 4, 446-456. doi: 10.1038/nrm1128

Riley, R. D., Heney, D., Jones, D. R., Sutton, A. J., Lambert, P. C., Abrams, K. R., et al. (2004). A systematic review of molecular and biological tumor markers in neuroblastoma. Clin. Cancer Res. 10, 4-12. doi: 10.1158/1078-0432.ccr-1051-2

Rohrer, H. (2011). Transcriptional control of differentiation and neurogenesis in autonomic ganglia. Eur. J. Neurosci. 34, 1563-1573. doi: 10.1111/j.1460-9568. 2011.07860.x

Russell, M. R., Penikis, A., Oldridge, D. A., Alvarez-Dominguez, J. R., McDaniel, L., Diamond, M., et al. (2015). CASC15-S is a tumor suppressor lncRNA at the 6p22 neuroblastoma susceptibility locus. Cancer Res. 75, 3155-3166. doi: 10.1158/0008-5472.can-14-3613

Rybak, A., Fuchs, H., Smirnova, L., Brandt, C., Pohl, E. E., Nitsch, R., et al. (2008). A feedback loop comprising lin-28 and let-7 controls pre-let7 maturation during neural stem-cell commitment. Nat. Cell Biol. 10, 987-993. doi: $10.1038 /$ ncb1759 
Sausen, M., Leary, R. J., Jones, S., Wu, J., Reynolds, C. P., Liu, X., et al. (2013). Integrated genomic analyses identify ARID1A and ARID1B alterations in the childhood cancer neuroblastoma. Nat. Genet. 45, 12-17. doi: 10.1038/ng.2493

Schilling, F. H., Spix, C., Berthold, F., Erttmann, R., Fehse, N., Hero, B., et al. (2002). Neuroblastoma screening at one year of age. N. Engl. J. Med. 346, 1047-1053. doi: 10.1056/NEJMoa012277

Schleiermacher, G., Javanmardi, N., Bernard, V., Leroy, Q., Cappo, J., Rio Frio, T., et al. (2014). Emergence of new ALK mutations at relapse of neuroblastoma. J. Clin. Oncol. 32, 2727-2734. doi: 10.1200/JCO.2013.54.0674

Schnepp, R. W., Khurana, P., Attiyeh, E. F., Raman, P., Chodosh, S. E., Oldridge, D. A., et al. (2015). A LIN28B-RAN-AURKA signaling network promotes neuroblastoma tumorigenesis. Cancer Cell 28, 599-609. doi: 10.1016/j.ccell.2015.09.012

Schramm, A., Koster, J., Assenov, Y., Althoff, K., Peifer, M., Mahlow, E., et al. (2015). Mutational dynamics between primary and relapse neuroblastomas. Nat. Genet. 47, 872-877. doi: 10.1038/ng.3349

Sebbagh, M., and Borg, J. P. (2014). Insight into planar cell polarity. Exp. Cell Res. 328, 284-295. doi: 10.1016/j.yexcr.2014.09.005

Shah, N. M., Groves, A. K., and Anderson, D. J. (1996). Alternative neural crest cell fates are instructively promoted by TGF $\beta$ superfamily members. Cell 85 , 331-343. doi: 10.1016/s0092-8674(00)81112-5

Shohet, J., and Foster, J. (2017). Neuroblastoma. BMJ 357:j1863. doi: 10.1136/bmj. j1863

Silversides, C. K., Lionel, A. C., Costain, G., Merico, D., Migita, O., Liu, B., et al. (2012). Rare copy number variations in adults with tetralogy of Fallot implicate novel risk gene pathways. PLoS Genet. 8:e1002843. doi: 10.1371/journal.pgen. 1002843

St Pierre, R., and Kadoch, C. (2017). Mammalian SWI/SNF complexes in cancer: emerging therapeutic opportunities. Curr. Opin. Genet. Dev. 42, 56-67. doi: 10.1016/j.gde.2017.02.004

Tang, L., Nogales, E., and Ciferri, C. (2010). Structure and function of SWI/SNF chromatin remodeling complexes and mechanistic implications for transcription. Prog. Biophys. Mol. Biol. 102, 122-128. doi: 10.1016/j. pbiomolbio.2010.05.001

Tang, X. X., Zhao, H., Robinson, M. E., Cnaan, A., London, W., Cohn, S. L., et al. (2000). Prognostic significance of EPHB6, EFNB2 and EFNB3 expressions in neuroblastoma. Med. Pediatr. Oncol. 35, 656-658. doi: 10.1002/1096$911 x(20001201) 35: 6<656$ ::aid-mpo37 > 3.0.co;2-a

Thiele, C. J., Li, Z., and McKee, A. E. (2009). On Trk-the TrkB signal transduction pathway is an increasingly important target in cancer biology. Clin. Cancer Res. 15, 5962-5967. doi: 10.1158/1078-0432.ccr-08-0651

Tsarovina, K., Pattyn, A., Stubbusch, J., Muller, F., van der Wees, J., Schneider, C., et al. (2004). Essential role of gata transcription factors in sympathetic neuron development. Development 131, 4775-4786. doi: 10.1242/dev.01370

Valentijn, L. J., Koster, J., Zwijnenburg, D. A., Hasselt, N. E., van Sluis, P., Volckmann, R., et al. (2015). TERT rearrangements are frequent in neuroblastoma and identify aggressive tumors. Nat. Genet. 47, 1411-1414. doi: $10.1038 /$ ng. 3438

Valteau-Couanet, D., Le Deley, M. C., Bergeron, C., Ducassou, S., Michon, J., Rubie, H., et al. (2014). Long-term results of the combination of the N7 induction chemotherapy and the busulfan-melphalan high dose chemotherapy. Pediatr. Blood Cancer 61, 977-981. doi: 10.1002/pbc.24713

Varley, J. E., and Maxwell, G. D. (1996). BMP-2 and BMP-4, but not BMP-6, increase the number of adrenergic cells which develop in quail trunk neural crest cultures. Exp. Neurol. 140, 84-94. doi: 10.1006/exnr.1996.0118

Varley, J. E., Wehby, R. G., Rueger, D. C., and Maxwell, G. D. (1995). Number of adrenergic and islet-1 immunoreactive cells is increased in avian trunk neural crest cultures in the presence of human recombinant osteogenic protein-1. Dev. Dyn. 203, 434-447. doi: 10.1002/aja.1002030406

Vernersson, E., Khoo, N. K., Henriksson, M. L., Roos, G., Palmer, R. H., and Hallberg, B. (2006). Characterization of the expression of the ALK receptor tyrosine kinase in mice. Gene Expr. Patterns 6, 448-461. doi: 10.1016/j.modgep. 2005.11.006
Viswanathan, S. R., Daley, G. Q., and Gregory, R. I. (2008). Selective blockade of microRNA processing by Lin28. Science 320, 97-100. doi: 10.1126/science. 1154040

Wang, K., Diskin, S. J., Zhang, H., Attiyeh, E. F., Winter, C., Hou, C., et al. (2011). Integrative genomics identifies LMO1 as a neuroblastoma oncogene. Nature 469, 216-220. doi: 10.1038/nature09609

Wang, X., Nagl, N. G., Wilsker, D., Van Scoy, M., Pacchione, S., Yaciuk, P., et al. (2004). Two related ARID family proteins are alternative subunits of human SWI/SNF complexes. Biochem. J. 383, 319-325. doi: 10.1042/bj20040524

Wartiovaara, K., Barnabe-Heider, F., Miller, F. D., and Kaplan, D. R. (2002). Nmyc promotes survival and induces S-phase entry of postmitotic sympathetic neurons. J. Neurosci. 22, 815-824. doi: 10.1523/jneurosci.22-03-00815.2002

Weiss, W. A., Aldape, K., Mohapatra, G., Feuerstein, B. G., and Bishop, J. M. (1997). Targeted expression of MYCN causes neuroblastoma in transgenic mice. EMBO J. 16, 2985-2995. doi: 10.1093/emboj/16.11.2985

Whittle, S. B., Smith, V., Doherty, E., Zhao, S., McCarty, S., and Zage, P. E. (2017). Overview and recent advances in the treatment of neuroblastoma. Expert Rev. Anticancer Ther. 17, 369-386. doi: 10.1080/14737140.2017.1285230

Wislet, S., Vandervelden, G., and Rogister, B. (2018). From neural crest development to cancer and vice versa: how p75(NTR) and (Pro)neurotrophins could act on cell migration and invasion? Front. Mol. Neurosci. 11:244. doi: 10.3389/fnmol.2018.00244

Wong, K., Ren, X. R., Huang, Y. Z., Xie, Y., Liu, G., Saito, H., et al. (2001). Signal transduction in neuronal migration: roles of GTPase activating proteins and the small GTPase Cdc42 in the Slit-Robo pathway. Cell 107, 209-221. doi: 10.1016/S0092-8674(01)00530-X

Woods, W. G., Tuchman, M., Robison, L. L., Bernstein, M., Leclerc, J. M., Brisson, L. C., et al. (1996). A population-based study of the usefulness of screening for neuroblastoma. Lancet 348, 1682-1687. doi: 10.1016/s01406736(96)06020-5

$\mathrm{Xu}$, Q., and Wilkinson, D. G. (2013). Boundary formation in the development of the vertebrate hindbrain. Wiley Interdiscip. Rev. Dev. Biol. 2, 735-745. doi: 10.1002/wdev.106

Yanagisawa, M., Yoshimura, S., and Yu, R. K. (2011). Expression of GD2 and GD3 gangliosides in human embryonic neural stem cells. ASN Neuro 3:e00054. doi: 10.1042/an20110006

Yu, A. L., Gilman, A. L., Ozkaynak, M. F., London, W. B., Kreissman, S. G., Chen, H. X., et al. (2010). Anti-GD2 antibody with GM-CSF, interleukin-2 and isotretinoin for neuroblastoma. N. Engl. J. Med. 363, 1324-1334. doi: 10.1056/NEJMoa0911123

Yu, J., Vodyanik, M. A., Smuga-Otto, K., Antosiewicz-Bourget, J., Frane, J. L., Tian, S., et al. (2007). Induced pluripotent stem cell lines derived from human somatic cells. Science 318, 1917-1920. doi: 10.1126/science.1151526

Yuan, J., and Yankner, B. A. (2000). Apoptosis in the nervous system. Nature 407, 802-809. doi: 10.1038/35037739

Zhu, S., Lee, J. S., Guo, F., Shin, J., Perez-Atayde, A. R., Kutok, J. L., et al. (2012). Activated ALK collaborates with $\mathrm{MYCN}$ in neuroblastoma pathogenesis. Cancer Cell 21, 362-373. doi: 10.1016/j.ccr.2012.02.010

Zimmerman, K. A., Yancopoulos, G. D., Collum, R. G., Smith, R. K., Kohl, N. E., Denis, K. A., et al. (1986). Differential expression of myc family genes during murine development. Nature 319, 780-783. doi: 10.1038/319780a0

Conflict of Interest Statement: The authors declare that the research was conducted in the absence of any commercial or financial relationships that could be construed as a potential conflict of interest.

Copyright (c) 2019 Johnsen, Dyberg and Wickström. This is an open-access article distributed under the terms of the Creative Commons Attribution License (CC BY). The use, distribution or reproduction in other forums is permitted, provided the original author(s) and the copyright owner(s) are credited and that the original publication in this journal is cited, in accordance with accepted academic practice. No use, distribution or reproduction is permitted which does not comply with these terms. 